\title{
CABALGANDO CAMBIOS Y CONTRADICCIONES: FRANCISCA DE LA MAZA, FERNANDA CASTRO Y JOAQUÍN MELINIIR SOBRE TURISMO Y TURISTIFICACIÓN EN CHILE
}

\section{LUIS FERNANDO ANGOSTO FERRÁNDEZ*}

\section{Resumen}

Pocas actividades económicas siguen proyectando una imagen tan amable como el turismo. Son muchos los que quisieran vivir como turistas (epítome del ideal comercial del no-trabajador); muchos otros viven o quisieran vivir del turismo (y de algo hay que vivir). Al mismo tiempo, y dejando las incertidumbres que la pandemia genera (¿qué irá a pasar con el turismo?), esta actividad social genera muchos polos de oposición, desde los que se pueden identificar en las llamadas "turismofobias" a los que se pueden escuchar entre grupos que ven ven en la expansión turística una nueva plataforma de profundización de desigualdades en el capitalismo contemporáneo.

Este trabajo permite reflexionar sobre estas cuestiones a partir de entrevistas a una antropóloga que estudia el turismo (Francisca de la Maza) y a jóvenes mapuche directamente involucrados en el desarrollo de actividades turísticas en sus comunidades (Fernanda Castro y Joaquín Meliñir).

\footnotetext{
* Académico, Departamento de Antropología y Estudios Latinoamericanos, Facultad de Artes y Ciencias Sociales, Universidad de Sydney, Australia.
} 


\section{Introducción}

Pocas actividades económicas siguen proyectando una imagen tan amable como el turismo. Los consumidores de servicios turísticos los ven frecuentemente como la materialización natural de la idea de vacación (fugaz tregua en la generalmente batallada "vida laboral"); los grandes empresarios como un ámbito de actividad en la que hacer caja a partir de los cambiantes pero inagotables deseos de expansión vital del sujeto moderno; los políticos como un potencial aliado en la generación de "marcas" (de país, región, ciudad, pueblo, barrio), aparentemente indispensables para la competitividad económica de las comunidades que los eligen; los conservacionistas como una posible llave maestra para lograr el difícil equilibrio entre protección y explotación económica de la naturaleza; y en muchas zonas de la periferia o semiperiferia del sistema mundo ha empezado a verse esta actividad como una nueva oportunidad para subirse al tren del desarrollo socioeconómico.

Por supuesto, para cada uno de estos vectores sociales que sostienen la imagen amable del turismo existen polos de oposición. Por un lado están los focos de "turismofobia" que crecen entre los que ven su derecho a la ciudad o al territorio erosionado por el impacto multidimensional del turismo. Por otro lado, las reflexiones de los que, involucrados directamente en la promoción de esta industria o desligados de ella, consideran que la expansión de la actividad turística debe ser evaluada a partir de análisis sustantivos de sus beneficios y riesgos.

Sobre estos temas se habló, y mucho, durante el $V$ Coloquio Internacional de Turismo, Pueblos
Indígenas, Comunidades tradicionales y Afrodescendientes (CTurTI), celebrado en noviembre de 2018 en Villarrica (Chile). Esta edición del coloquio, coordinado por la antropóloga chilena Francisca de la Maza y apoyado, entre otras instituciones, por la Pontificia Universidad Católica de Chile y por el Centro de Estudios Interculturales e Indígenas (CIIR) de ese país, tuvo como temática vertebradora "Derechos Indígenas, Territorio y Desarrollo en Contextos Turísticos". El evento abarcó tres días y reunió en mesas redondas y talleres a cientos de participantes de varios países (Chile, Argentina, Brasil, España, Paraguay), incluyendo miembros de comunidades indígenas que desarrollan proyectos turísticos, consultores trabajando para ONGs y para empresas, estudiantes, funcionarios públicos, representantes de fundaciones privadas, académicos, investigadores y vecinos de Villarrica y alrededores.

La composición heterogénea de las Mesas y Talleres tuvo reflejo en la amplitud de temas abordados y en la variedad de perspectivas sobre el potencial y los retos que el turismo plantea en comunidades indígenas y afrodescendientes. Las entrevistas que aquí se presentan son una pequeña pero iluminadora muestra de estos temas y perspectivas, que en conjunto permitieron atisbar el fenómeno turístico como un proceso social poliédrico. Dos de las entrevistas nos las brindaron jóvenes mapuche directamente involucrados en el desarrollo de actividades turísticas en sus comunidades, y nos permiten conocer sus motivaciones y la perspectiva con la que trabajan en dichas actividades: Fernanda Castro, pewenche de la comunidad de Callaqui en el alto Biobío, especializada en rafting; y Joaquín Meliñir, pewenche de la comunidad de 
Quinquén (comuna de Lonquimay), miembro de una asociación gremial que promueve el turismo mapuche. La tercera entrevista nos la ofrece Francisca de la Maza, que lleva varios años desarrollando un novedoso proyecto de investigación sobre los procesos de turistificación en territorios indígenas en Chile.

En su entrevista, Joaquín Meliñir plantea que, entre los mapuche, podría verse al turismo como el caballo fue visto por Lautaro (famoso líder mapuche del siglo XVI) —un elemento traído por los españoles pero que podía ser utilizado en las luchas contra la desposesión territorial. Siguiendo esa imagen, escuchemos a nuestros entrevistados hablar del turismo que hoy cabalga por todo Chile.

\section{Fernanda Castro Purrán}

Luis Fernando Angosto Ferrández [LFAF]: ¿Podrías presentarte a nuestros lectores y resumir qué es lo que has venido a presentar en el coloquio?

Fernanda Castro Purrán [FCP]: Soy Fernanda Castro Purrán, pewenche de la comunidad de Callaqui, de la comuna de Alto Biobío. Soy docente de turismo, prontamente guía de rafting y también guía de montaña. Hago educación al aire libre, soy parte de un equipo de rafting femenino de Alto Biobío y hoy vine a presentar la experiencia de cómo hemos utilizado el rafting y el kayak como una herramienta de educación relacionada con los recursos fluviales de nuestro patrimonio cultural pewenche. Además de eso, vemos el rafting y el kayaking como elementos de aventura dentro del desarrollo turístico de la comuna.
[LFAF]: ¿Te importaría explicar cómo llegaste al rafting en concreto? Mencionabas en tu exposición que, creciendo con ríos alrededor, de niños os lanzabais algunos al río con lo que tuvieseis a mano, pero que nunca os habías planteado hacer rafting. ¿Cómo empezáis a pensar que el rafting puede ser una oportunidad de trabajo?

[FCP]: Cuando vi las primeras balsas bajar por el Bío Bío tenía como 7 años. Con mi familia nos íbamos a bañar a las orillas del Bío Bío y siempre pasaban estos gringos en sus balsas, nos saludaban. Y pasó que una vez uno de los gringos tuvo un accidente y mi abuela, que era componedora de huesos, le ayudó; y entonces, en paga, en trueque por haberle sanado mi abuela, el gringo nos invitó a pasear en la balsa. Yo fui con mis primos, disfrutando más que nada el deporte. Después de eso inflábamos cámaras de rueda de vehículos y tratábamos de imitar el rafting como cruzando el río, sin tener en cuenta el riesgo que podía producir eso. Más tarde, un amigo me invitó a hacer rafting al río Trancura en Pucón y ahí fue la primera vez que hice rafting de verdad. Luego participé en un festival de ríos que se hace en Alto Biobío, "Biobío Vive", con un grupo de amigas participamos. Nos invitaron a conformar un equipo local y, sin tener mayor conocimiento técnico sobre el deporte, a competir con otras mujeres que vienen de otros países y que tenían experiencia en el deporte. Competimos y logramos el segundo lugar, y desde ahí nos creamos un nombre, nos Ilamamos Malen Leubü, que significa niñas del río. En su momento éramos puras mujeres pewenche y con el tiempo se han ido sumando otras mujeres que no lo son pero que viven en el territorio, y desde ahí hemos ido generando instancias de educación sobre el río. 
Nuestro afán, más que competir, es generar instancias educativas, darle el espacio a los niños, a los jóvenes del territorio para que aprendan sobre sus cuencas, para que entiendan también los componentes fluviales de un río, que sepan cómo nace un río, cómo se crea, por qué es importante protegerlo, cuál es la importancia que tiene para nosotros como pewenche. $Y$ desde ahí hemos ido generando encuentros con otros ríos del país.

Luego conocí, dentro del río también, en una de estas actividades que hacíamos, a un gringo que es director de una ONG que se llama Ríos to Rivers y que en su momento estaba haciendo intercambios culturales con jóvenes de diferentes países y de diferentes cuencas, principalmente cuencas amenazadas por represas. Me invitó a participar con estudiantes de otros lugares, y nos juntamos en la Patagonia, donde recorrimos durante 6 días el río Baker, bajamos hasta Caleta Tortel. Hoy en día seguimos siendo parte de esa ONG. Yo, como representante del Bío Bío en Chile, estoy preparando nuestra nueva travesía e intercambio para el 2019, en la que vamos a hacer el recorrido que hacían los primeros extranjeros que recorrieron el Bío Bío cuando era el exponente mundial del rafting. Vamos a salir desde el nacimiento del Bío Bío hasta llegar a Ralco y desde ahí vamos a bajar el río Nuble, y en este encuentro participarán jóvenes del Biobío, de la Patagonia, del río Santa Cruz de Argentina y también del río Klamath de Estados Unidos de las tribus indígenas karok y yurok.

[LFAF]: ¿Cómo resumirías la contribución que puede hacer el turismo indígena a las comunidades pewenche? Has hablado de que es una herramienta para el aprendizaje para los niños. ¿Algún otro beneficio que puede aportar esta experiencia?

[FCP]: Es una oportunidad de desarrollo local, un emprendimiento nuevo enfocado en la aventura, pero también en la educación. Nuestra idea es que las comunidades puedan conocer el rafting como un deporte, que se den cuenta de que es un buen elemento para generar nuevos emprendimientos, traer más turistas al territorio, educar en base a nuestra cultura y dar a conocer nuestra cultura a través de este deporte. Queremos que los emprendedores se motiven a generar sus propias empresas de rafting, a utilizar el recurso natural del río propio como algo de ellos, porque actualmente hay empresas de rafting que tienen bajadas comerciales en el Bío Bío, pero ninguna es de la zona. Obviamente lo vemos también como una oportunidad de desarrollo para turismo pewenche. Más que entenderlo solo como un deporte de aventura y de que las personas vayan a disfrutar, lo vemos como una oportunidad de educar a los turistas en torno a la importancia del río para nosotros los pewenche.

[LFAF]: Durante el coloquio ciertamente se ha hablado de los beneficios que puede presentar el turismo en comunidades indígenas, pero también en algunos casos de los riesgos que se presentan. ¿Vosotras habéis identificado alguno en concreto en tu comunidad? ¿Os enfrentáis a retos imprevistos?

[FCP]: Existe todavía mucha dificultad al momento de presentar el proyecto en algunas comunidades, porque desde que se hicieron las centrales hay comunidades que están totalmente cerradas a vincularse a cierto tipo de novedades, a incorporarlas a su propia 
comunidad. Se produce este miedo de crear algo nuevo, eso ha sido lo principal. Pero también está la otra parte de la gente que ha demostrado el interés y también la motivación por querer apoyar este proyecto, y frente a este apoyo las dificultades que vemos a grandes rasgos son las diferentes amenazas que están llegando de a poco a nuestro territorio: la construcción de una carretera hídrica que amenaza el río limpio que es el Queuco.

\section{[LFAF]: ¿Algo que quisieses añadir?}

[FCP]: Como dije en mi presentación, creo que, como emprendedores de territorios mapuche, si queremos generar un cambio social dentro de nuestros territorios tenemos que preocuparnos por la educación de nuestros niños, de nuestros jóvenes, enseñarles a ellos cual es la importancia de preservar nuestra cultura, de utilizar el turismo como una herramienta de desarrollo, pero también con cuidado para que sea sustentable, que sea de manera respetuosa y podamos trabajar todos en conjunto, en comunidad.

\section{Joaquín Meliñir Huaiquillán}

[LFAF]: Joaquín, te presentabas durante el coloquio como miembro de la Sociedad de Turismo Mapuche AG. ¿Te puedes presentar tú mismo brevemente para los lectores de esta entrevista, y contarnos qué es esta asociación y qué haces tú dentro de ella?

Joaquín Meliñir Huaiquillán [JMH]: Mi nombre es Joaquín Meliñir Huaiquillán, soy mapuche pewenche de la comunidad indígena de Quinquén, comuna de Lonquimay, la región de La Araucanía. Soy un emprendedor mapuche que está trabajando el desarrollo del turismo mapuche en la comunidad, pero al mismo tiempo soy presidente de la Sociedad de Turismo Mapuche de La Araucanía.

[LFAF]: ¿Y cuál es el origen y el recorrido que tiene esta sociedad?

[JMH]: La sociedad es un gremio formado recientemente, pero venimos trabajando con los socios de este gremio desde hace cuatro años, a través de distintas instancias de capacitación, sobre todo en temas de poder abordar los negocios indígenas a nivel regional. En eso hemos especializado este gremio para abordar el tema del turismo mapuche.

[LFAF]: ¿Cuántos miembros tiene la asociación ahora?

[JMH]: La asociación tiene ahora 35 socios, todos registrados como empresas mapuche que están formalizadas, hoy en día facturando, y que trabajan distintos rubros como gastronomía, alojamiento, productos de souvenir o actividades recreativas.

[LFAF]: Y la motivación que tuvisteis al crear la asociación, ¿cuál era? ¿tenías alguna inquietud específica? ¿qué se persigue con la sociedad?

[JMH]: Bueno, la sociedad nace al alero de la Cámara de Comercio mapuche, donde está siendo apoyada por un equipo multisectorial, y sobre todo profesional, mapuche. Este equipo ha impulsado el trabajo de la sociedad de turismo mapuche, y tenemos un gerente que es Javier Lefimán que ha sido nuestro director ejecutivo liderando desde la Cámara de Comercio. 
Esto ha hecho que también podamos especializarnos en el área de turismo como Sociedad de Turismo Mapuche de La Araucanía. Le debemos mucho a Javier que es un profesional mapuche que ha recorrido mundo, que tiene mucha experiencia en desarrollo económico y que por eso ha facilitado que nosotros podamos juntarnos para generar este gremio con distintos emprendedores y empresas mapuche de tres territorios: el territorio lafquenche, el territorio huenteche y el territorio pewenche, que es de donde yo vengo.

[LFAF]: Te quería preguntar sobre algunos de los puntos que tocaste hoy en tu intervención en el coloquio. En primer lugar, ¿qué te pareció este coloquio sobre turismo celebrado aquí en Villarrica?

[JMH]: Muy interesante, y quisiera agradecer al centro de investigación de la Universidad Católica que ha hecho posible el desarrollo de esta actividad y que nos ha hecho partícipes. Hemos venido a presentar y a conocer experiencias de otros pueblos originarios de Chile y de otras partes de Latinoamérica, y estamos conociendo las distintas visiones de turismo indígena y cómo este turismo lo podemos aterrizar en nuestra realidad, en este caso a la región de La Araucanía. Nos proporciona herramientas que a nosotros nos sirven para poder ir mejorando el trabajo que nosotros vamos llevando como representantes de este gremio.

[LFAF]: Y en relación a eso, Joaquín, cerraste tu presentación con una imagen de un grabado en el que aparecía Lautaro junto a su caballo, y utilizaste esa imagen como metáfora del potencial del turismo en comunidades mapuche. ¿Puedes explicar de dónde viene esa reflexión, esa idea de que el turismo puede ser visto como algo que viene de fuera (como el caballo llegó al territorio de Lautaro en su día) pero que se convierte en una herramienta de lucha?

[JMH]: Sí, en uno de los talleres que hemos tenido como Sociedad de Turismo Mapuche, en algún momento se nos preguntó quién sería nuestro mentor, y uno de los mentores que más se repetía era Lautaro. Lautaro como un ejemplo para poder reconstruir nuestra memoria histórica, y a través de esta reconstrucción poder valorar la acción de Lautaro: traer el caballo como una herramienta de lucha para el pueblo mapuche. Nosotros queremos que el turismo pueda servir como nuestra herramienta de lucha para poder conservar nuestro territorio, para poder revitalizar nuestra lengua, para poder abordar todas las temáticas que tienen que ver con el tema de la conservación o con el respeto de nuestra cultura. Esto puede ser abordado a través de esta forma de lucha que dio Lautaro al incorporar al caballo, domesticándolo, que por cierto lo domesticó mejor que el español. ¿Por qué? Porque se conectó espiritualmente con el caballo, y el español veía al caballo solamente como un elemento servicial. El mapuche no solamente lo vio como un elemento servicial, sino que lo vio como su partner, como su amigo y se conectó con él espiritualmente. Eso es lo que yo quiero dejar claro, que el turismo nosotros lo podemos desarrollar de mejor forma que cualquier otra persona, porque tenemos dos conocimientos: el conocimiento mapuche y el conocimiento occidental.

[LFAF]: En relación a este símil que estás presentando, ¿le ves algún peligro a este caballo (el turismo) en estos momentos? Varios de los intervinientes en el coloquio han hablado de que puede haber algunos 
peligros asociados al turismo, a ese caballo que en principio se puede domesticar. Tú, o más ampliamente la asociación en la que trabajas, ¿identificáis en estos momentos algún riesgo en particular que os parece preocupante, algo a lo que habría que hacer seguimiento específico?

[JMH]: Sí, de todas maneras, porque nosotros, la conversa y la discusión que hemos tenido con nuestra propia gente es sobre cómo nosotros podemos evitar que el turismo se convierta en una amenaza. Se presente como una oportunidad, pero esta oportunidad tenemos que trabajarla con responsabilidad. Un trabajo bien planificado en cada territorio, que tenga que ver con el respeto mutuo y a la cultura, y que esto no se transforme también en una folclorización de lo que nosotros somos como mapuche.

[LFAF]: También mencionaste en tu intervención algo que se ha escuchado en otras intervenciones: la idea de que la cultura también se puede utilizar como recurso en esta lucha en la que entra el turismo. $Y$ hablaste en concreto sobre la puesta en valor de los relatos de las comunidades pewenche $y$ sobre el relato particular que tiene cada territorio. ¿A qué te refieres con poner en valor los relatos de las comunidades?

[JMH]: Poner en valor los relatos tiene que ver con cómo el pueblo mapuche primero que nada tiene distintos territorios y en cada territorio hay elementos particulares. $Y$ esos elementos particulares tienen que ver con la historia, y la historia tiene que ver con un relato asociado, y ese relato tiene que ver también con educar al visitante que llega al territorio; cómo nace un territorio, cómo vive un territorio, cómo se plantea en el desarrollo del turismo.
[LFAF]: ¿Añadirías algo que no te gustaría dejar en el tintero?

[JMH]: Solamente agradecer esta gran oportunidad que tenemos de visibilizar el turismo mapuche que va creciendo y que queremos que sea un sello y una marca reconocida a nivel nacional y a nivel internacional.

\section{Francisca de la Maza}

[LFAF]: La primera pregunta que te quería hacer tiene que ver con tu nuevo proyecto de investigación, que es novedoso dentro de la antropología chilena por su enfoque en el turismo indígena. ¿Podrías señalar cuál fue la razón que te llevó a hacer este trabajo y por qué crees que anteriormente este tema no se había trabajado demasiado en Chile?

Francisca de la Maza [FdM]: Bueno, la investigación que estoy realizando la defino más bien como enfocada en la turistificación de los territorios indígenas, más que en turismo indígena, aunque obviamente hay una tendencia a hablar de esto último por los vínculos que tengo establecidos con organizaciones o familias indígenas que trabajan en turismo. Pero el foco está en la turistificación de los territorios indígenas. Entiendo por turistificación el proceso a través del cual territorios históricamente pertenecientes a pueblos indígenas en diferentes partes de Chile se han ido transformando a partir del turismo, con la llegada del turismo, tanto real como potencial. Esto último es lo que está ocurriendo en La Araucanía. Y es un enfoque novedoso para la antropología 
chilena porque sobre turismo hay muy pocos trabajos publicados por antropólogos, contados con los dedos de las manos. Los que existen, abordan el fenómeno en territorios muy específicos como San Pedro de Atacama, o turismo mapuche y pewenche en el sur chileno. No hay una bibliografía amplia.

[LFAF]: ¿Y a qué crees que se debe esa situación cuando el turismo es un fenómeno que claramente está impactando el país desde hace años.

[FdM]: Yo creo que la antropología en Chile tiene una tendencia a ser muy clásica en su definición de temas de estudio, y los focalizados en pueblos indígenas, que son abundantes, han abordado ámbitos específicos de la política y cultura de algunos pueblos, fundamentalmente el mapuche y el aymara. Se han ido ampliando los temas hacia el mundo urbano, y hoy día hacia cuestiones específicas como la migración. El turismo ha sido invisibilizado por la antropología. Y de hecho a mí me costó mucho conseguir financiación para mi proyecto sobre turismo, postulé varias veces hasta que la conseguí a través de FONDECYT (Fondo Nacional de Desarrollo Científico y Tecnológico); ya es difícil en general por lo competitivo del proceso de acceso a fondos públicos, pero quizá las temáticas novedosas presenten incluso más dificultades. Tal y como ocurre en otros países, hay como un sentido común que asocia al turismo con el ocio, con el viaje, con el paseo, como decimos en Chile. Como un pasatiempo, por así decirlo, algo que no se ve como un fenómeno político.

[LFAF]: Y para los propios antropólogos, ¿crees que puede haber pesado el lastre que asocia también al turismo con formas de inautenticidad cultural?

[FdM]: Claro, se ve asociado a una puesta en escena de la otredad. No ha habido una mirada más política, y el turismo es un fenómeno político que está transformando hoy en día muchos y variados territorios; es parte de una tendencia mundial, no solamente de Chile.

[LFAF]: Esto me sirve para enlazar tu proyecto actual sobre turistificación con tu trabajo antropológico anterior. Leyendo tus trabajos uno se da cuenta que, en parte, has continuado etnografiando la práctica estatal a la hora de mirar lo que está pasando con el turismo. Porque en tus trabajos recientes pones el foco en varios actores, pero desde luego también en agencias estatales que inciden en los procesos de turistificación. ¿Hasta qué punto las agencias estatales condicionan estos procesos, y hasta qué punto también agentes locales, indígenas y no indígenas, se relacionan con dichas agencias?

[FdM]:Las investigaciones que había realizado antes venían de mi tesis de maestría, doctorado, e incluso de pregrado, y estaban muy ligadas al estudio del Estado como construcción política, no necesariamente construcción cultural, que es algo que también exploré en los últimos año. Seguía inicialmente una línea muy clásica en la antropología chilena: estudiar la relación estado y pueblos indígenas. La novedad que yo incorporé fue la de analizar también el Estado como una construcción cultural desde la etnografía del Estado. Eso también en su tiempo fue relativamente nuevo, en el sentido de que desnaturalizaba la concepción del gran Estado y la del 
conflicto del Estado con el pueblo mapuche. Yo estudiaba la construcción del Estado a través del estudio de procesos locales y cómo esos procesos también afectaban una parte de la cotidianidad de las personas. Ese fue un aporte también en su momento, y completé un proyecto Fondecyt alrededor de ese tema. Ahí es donde yo me focalicé claramente en estudiar el rol que tenían los funcionarios en las acciones estatales cotidianas, ya sea a nivel de gobiernos locales o a nivel de interacciones sociales con los ciudadanos en programas que se implementan. Eso me llevó poco a poco a ver cómo el turismo iba tomando fuerza, porque me focalicé en los programas de desarrollo rural. Ahí me di cuenta que dentro de los discursos de los funcionarios, principalmente agrónomos, veterinarios, técnicos agrícolas, se iba incorporando el turismo como una opción que ellos ofrecían dentro de sus programas a las comunidades indígenas, en este caso a comunidades mapuche. Entonces me empezó a entrar la idea de que el turismo estaba siendo parte del discurso de la acción estatal, y a medida que fue pasando el tiempo también lo vi comparativamente en otros territorios de Chile. Me di cuenta que desde las políticas públicas hacia los pueblos indígenas ya no podía ceñirme a la idea de "política indígena", que era lo que yo había estudiado; se estaba instalando el concepto de "turismo indígena" o "turismo en los territorios indígenas".

La perspectiva que yo venía desarrollando, muy focalizada en la acción estatal, era limitada: estaba viendo la turistificación de los territorios indígenas y necesitaba poner el foco no solamente en el Estado (que ciertamente puede ser y es un actor fundamental), sino también sobre otros actores que son claves en esta forma de desarrollo. El enfoque sigue siendo el mismo, pero ya hay múltiples actores que están incidiendo en un mismo proceso y se conjugan, dialogan, se enfrentan; cambian los protagonismos según el contexto específico. Ahí tenemos, por ejemplo, los académicos, o las universidades (que puede que tengan fondos del Estado, pero los ejecutan ellas). Se incorpora así un discurso diferente al del Estado, y uno puede ver los procesos de contención y los procesos de disrupción de un discurso más hegemónico. También está el caso de las consultoras, o el de los tour operadores que tienen un rol fundamental en cómo se ofrece un tipo determinado de turismo. También están los propios emprendedores indígenas, que es el término que se utiliza acá en Chile: van asumiendo el desarrollo del turismo y se enfrentan y dialogan y se acomodan también a estos discursos hegemónicos.

En el fondo, mi transición consistió en pasar de mirar las construcciones culturales que se dan a partir de las interacciones entre actores estatales y ciudadanos a aplicar ese mismo enfoque a otros actores, a otros agentes que están en este proceso y que están dialogando. Es una mirada un poco más compleja y también sigue siendo política. Por eso lo veo como una continuidad de mi trabajo anterior, pero ahora más abierta a otros agentes.

[LFAF]: En relación a la multiplicidad de agentes estatales que uno encuentra en el ámbito del turismo hoy en día, ¿por qué crees que se ha generado? Porque, por un lado, demuestra que hay mucho interés en fortalecer el sector turístico en territorios indígenas, pero por otro lado lo que uno encuentra es que no es fácil explicar cómo 
hay tanta diversidad de agencias estatales remando, en principio, hacia la misma dirección desde diferentes ángulos. Y uno identifica, como mencionas en algunos de tus trabajos (2016, 2018a), a CONADI (Corporación Nacional de Desarrollo Indígena), por ejemplo, que es una agencia especializada en política de pueblos indígenas; pero también tienes a INDAP (Instituto de Desarrollo Agropecuario), a SERNATUR (Servicio Nacional de Turismo), CORFO (Corporación de Fomento de la Producción), CONAF (Corporación Nacional Forestal) y otras agencias y programas estatales que, a partir de los 90, pero particularmente a partir de los 2000, han hecho inciso en un momento $u$ otro en la necesidad de desarrollar programas de turismo indígena. ¿Por qué esa multiplicidad? ¿Qué nos dice esta multiplicidad sobre el aparato estatal? ¿Y qué incidencia real crees que tienen esa multiplicidad de agentes estatales en la conformación de procesos turísticos y en la economía nacional?

[FdM]: El estudio del turismo es una entrada para estudiar el Estado. Podríamos hacerlo también con otro tipo de políticas de desarrollo económico. Lo que me ha permitido el estudio del turismo es justamente desnaturalizar la idea de Estado, mostrar que el Estado no es homogéneo, ni tiene un discurso único, sino que es contradictorio en sí mismo. He encontrado divergencias entre los discursos en los diferentes niveles de la administración estatal, a nivel local, regional y nacional. Uno puede apreciar que las políticas no son planificadas armoniosamente; esto tiene que ver con las historias de las instituciones. Se podría hacer la genealogía de las instituciones y entender muy bien por qué cada institución tiene un discurso diferenciado sobre el turismo. La CONADI tiene un foco básicamente orientado el fortalecimiento cultural y tiene que ver con su origen, de dónde viene, quienes son los funcionarios que trabajan en ella. Lo mismo con INDAP, por ejemplo. La CONADI tiene este enfoque más culturalista de fortalecer la cultura, la identidad indígena, y para INDAP el foco siempre ha sido el desarrollo productivo. De hecho, a INDAP le costó mucho incorporar la variable cultural en algunos programas anteriores, pero hoy día lo ha incorporado, siempre con este foco productivo. En cambio SERNATUR, por lo menos a nivel regional, tiene un discurso mucho más centrado en la experiencia turística, en el encuentro intercultural.

El enfoque del turismo permite justamente ver que hay esta discordancia. Cuando se generan instancias como las Mesas de Turismo Mapuche, o la Mesa de Turismo Indígena nacional como la que se generó en Santiago con varias instituciones participantes, se generan estas divergencias y conflictos, que son también de intereses, porque muchas veces la que pone la plata es una institución determinada y eso le permite tener más influencia. Por eso se hacen estos convenios entre instituciones, que generan una negociación entre los propios funcionarios. Si uno analiza el Estado desde ese nivel (desde "arriba") y luego analiza cómo se implementan a otros niveles los planes diseñados arriba, se entienden muy bien los procesos políticos que se están desarrollando en diferentes territorios, y también las contradicciones que esos procesos albergan. Porque finalmente lo que ha llevado a estas diferencias conceptuales sobre lo que es el turismo indígena y sobre cómo distribuir los fondos que se le asignan (porque 
finalmente esto se traduce en partidas de fondos para programas específicos), es que en cada región hay formaciones sociales parcialmente distintas. En el caso de la región de La Araucanía se han desarrollado una cantidad enorme de acciones de formación, de focalización, de programas de desarrollo orientados al turismo que son divergentes, complementarios y simultáneos a la vez.

Vemos emprendedores mapuche que han participado en una cantidad importante de programas de formación y que son parte de múltiples redes simultáneamente. Y uno ve así como la acción disgregada del Estado también tiene ecos en la acción del ciudadano común y corriente que uno podría verlo como pasivo. Hay quien plantea estos temas bajo la idea de "ah, este pobre ciudadano que está recibiendo directivas y es manipulado por las instituciones". Pero eso no es lo que pasa. Lo que pasa es que las organizaciones se apropian, y quizá instrumentalmente muchas veces por intereses políticos, de estas oportunidades que ofrece el contexto donde el turismo indígena pasa a ser un tema relevante a nivel de políticas públicas. Se apropian de una oportunidad como esta para otros fines, no solamente para mejorar su emprendimiento turístico; también se aprovechan para reforzar otros procesos de reivindicación de liderazgos a nivel local y a nivel regional.

Esta forma de estudiar el Estado también permite ver que las políticas nacionales van a un ritmo diferente al de las políticas regionales y a las del nivel local comunal. Lo que vemos en el caso del turismo mapuche, y esto es algo que he tratado en un artículo reciente (2018b), es que va mucho más allá del "turismo indígena". El turismo mapuche se construye a partir de un diálogo a nivel regional con actores claves que son funcionarios totalmente empoderados, que creen firmemente que el turismo mapuche es una oportunidad tanto para la convivencia intercultural como para el desarrollo productivo y para fortalecimiento identitario mapuche. $Y$ estos funcionarios promueven un proceso participativo con diferentes actores, e instalan, en colaboración activa con los emprendedores de turismo mapuche, el concepto de "turismo mapuche". Esta denominación se gesta entre el 2007-2010, y hoy día en la región de La Araucanía se habla de turismo mapuche. A nivel nacional el concepto que se instala en 2015 es el concepto de "turismo indígena", y se genera con intermediadores que no son locales sino externos. Estos generan e incentivan un tipo de concepto y de acción que es mucho más de arriba a abajo. Entonces hoy en día tenemos estas dos concepciones que conviven: una región donde se habla de turismo mapuche y, a nivel nacional, el concepto turismo indígena como guía de trabajo. Los diálogos y puntos de encuentro son pocos, y eso genera también distancia entre los diferentes niveles del Estado en el espacio local, y también desconocimiento de ambos lados de muchas de las acciones que se hacen tanto a nivel local como a nivel nacional.

[LFAF]: Siguiendo con la emergencia de la etiqueta "turismo mapuche", también hemos visto recientemente que en otras regiones se están afianzado otros tipos de etiqueta. Está por ejemplo el caso de la "marca", que es la etiqueta preferida por algunos de los implicados en estos procesos. Por ejemplo, hablan de "marca mapuche" algunos de los actores vinculados al turismo mapuche, y también se escucha hablar de la "marca rapa nui”. Tú también has hecho trabajo de campo 
en Rapa Nui, y en esta isla se está viendo un proceso de turistificación clarísimo, pero en ese caso con un control mucho más fuerte de la población local sobre dicho proceso. En uno de tus artículos (2018a) comparas el turismo en San Pedro de Atacama con el de La Araucanía y el de Rapa Nui, y hablas, por ejemplo, de cómo en este último caso los habitantes de la isla consiguieron en un momento dado la co-gestión (en asociación con la agencia estatal encargada de los parques naturales) del Parque Nacional Rapa Nui. Esto se dio a través de un proceso de reclamo de la población local que incluyó la protesta activa y también la ocupación del parque. Ahora ya se ha confirmado lo que tú apuntabas en el artículo: el Estado ha dado una concesión total de la gestión del parque al pueblo rapa nui - válida durante décadas-. Lo que parece apreciarse en ese proceso es que la organización política pre-existente en Rapa Nui fue clave para conseguir el control del Parque porque facilitó la movilización de protestas y una acción colectiva bastante organizada. $Y$ esto es contrastable con el caso del turismo mapuche en La Araucanía, pues la existencia entre los mapuche de diferentes redes de organización parece haber encontrado reflejo en un acceso más fragmentado por parte de la población mapuche a los espacios de negociación de los programas de desarrollo turístico. Y en el norte, en Atacama, el hecho de que haya tanta aparente desorganización y tanta falta de regulación en el ámbito del desarrollo turístico puede también tener una relación con la falta de organización política pre-existente entre, por ejemplo, población likanantai y en general en las comunidades atacameñas. ¿Crees que podríamos hacer esa relación de que a mayor organización política, mayor potencial control del desarrollo turístico?

[FdM]: Sí. Respecto a la cuestión de la marca yo creo que hay harta influencia de los modelos de otros países, por ejemplo de Nueva Zelanda. En el caso rapa nui es obvio, porque además son parte de la familia polinésica y hay mucho vínculo con toda la zona. Cuando se empieza a instalar este concepto de marca también se está recibiendo financiamiento de instituciones públicas, de CORFO básicamente. $Y$ hay una gran cantidad de programas y acciones encaminadas a construir un destino turístico diferenciado.

Rapa Nui es una isla, y tiene un atractivo internacional indiscutible. Sus habitantes han intentado desarrollar una planificación para consolidar ese potencial construyendo un "destino". Y eso, siguiendo otras experiencias internacionales, se genera a través de una marca, una marca que unifique los diferentes atractivos del lugar y construya destino, básicamente.

En San Pedro de Atacama eso es prácticamente inexistente porque la marca se da por sí sola, no necesita la construcción, por lo menos por el momento. Este lugar ya funciona como destino consolidado, vinculado al paisaje, a la naturaleza, y no necesariamente a lo cultural, a lo likanantai o a lo atacameño. La marca está instalada como "San Pedro de Atacama" y "el desierto de Atacama", con sus paisajes asociados. Hay un incipiente intento de reconstruir el lugar como destino parcialmente diferente. El sistema de mercado instaló el turismo en aquel lugar sin necesidad de planificación previa, porque es un desierto y, entre comillas, es "ilimitado". No tiene el problema de 
la isla de Rapa Nui, que es un sector totalmente cerrado y que tiene muchos problemas si el uso del mismo no se controla. Por eso hoy día está en Rapa Nui el tema de la ley de control de migraciones, el tema de regulación de las basuras que se producen. En cambio, en San Pedro todavía perdura esta visión de lo infinito asociado al desierto, y eso pareciera que aleja la percepción de potenciales problemas.

Y en el caso de la región de La Araucanía yo creo que la preocupación por la marca viene de una experiencia de turismo mapuche, pero también que ese concepto se instala. Tuvimos la experiencia de un seminario donde una persona de España increpaba a la gente: “¿qué es esto de turismo mapuche?”, les decía; "ustedes tienen que hablar de turismo indígena, ¡el turismo mapuche no existe en ninguna parte!". Increpaba a los propios mapuche que habían estado durante ocho o diez años trabajando sobre este concepto de turismo mapuche y les decía "eso no existe", "ustedes tienen que hablar de turismo indígena porque eso es lo que vende". Frente a esto se produce una reacción de la población local que plantea "no, lo nuestro es turismo mapuche", tiene que ver con la historia del pueblo mapuche, y eso lo queremos fomentar.

Ha habido también muchos cursos de formación para emprendedores y en general personas interesadas en la vía turística. Y también hay una incidencia estatal tremenda por medio de intermediarios estatales como universidades o consultoras o fundaciones. Como resultado se instala esta idea de que es necesario consolidar la marca mapuche, y también reforzada por los vínculos internacionales que han desarrollado los emprendedores mapuche en viajes a lugares como Nueva Zelanda o Canadá, donde han visto que existe una marca. Por ejemplo, el caso maorí es paradigmático. Uno llega al aeropuerto y están los símbolos maoríes, llegan las líneas aéreas y tienen el símbolo maorí. Eso ha servido como inspirador también para el caso mapuche, sobre todo en los programas de turismo actuales.

Ahora, respecto al control territorial que se ejerce en relación a diferentes modelos de turismo, llama mucho la atención que dos pueblos, el rapa nui y el likanantai, por diferentes vías, habían llegado a un nivel donde habían logrado tener un control de los accesos turísticos principales. En el caso de los likanantai, por medio de la concesión de los sitios de atracción turística: hay organizaciones o ayllus asociados a determinados centros turísticos, y eso se había definido a partir de una demarcación territorial que se hizo a principios de los 90' por medio de la CONADI.

[LFAF]: Llama la atención en el caso de San Pedro, ciertamente. Porque algunas comunidades tienen allí concesiones y control de gestión de lugares de visita como, por ejemplo, la laguna Céjar, por nombrar uno de los puntos de mayor atracción en la zona. $Y$ en ese caso es una comunidad atacameña la que tiene control sobre el acceso y la gestión de la laguna, mientras que, por ejemplo, en el concurrido Valle de la Luna es una asociación que agrupa a miembros de seis comunidades de la zona. Se aprecia una clara diferencia en el modelo de gestión si lo comparamos con el caso rapa nui. En Atacama no existe nada parecido a una organización supra-comunal que represente a un pueblo indígena, sino que son ayllus 
particulares o comunidades territorializadas las que crean y mantienen derechos sobre la explotación y mantenimiento de lugares con atractivo turístico. Pero este tipo de modelos, en cualquier caso, no garantiza que haya ningún tipo de redistribución formal de los potenciales beneficios obtenidos por los gestores de la atracción, que no llegan a comunidades aledañas. ¿Qué nos puedes decir sobre estos aspectos del modelo turístico en Atacama?

[FdM]: Efectivamente, hay modelos de implementación diferenciables, y los acuerdos que los sostienen son diferentes también. En el Valle de la Luna el acuerdo es más bien que las ganancias se invierten en el personal y en la mantención de los sitios, o sea, el excedente se invierte en el propio parque, o en la propia reserva en este caso, entonces tampoco hay una redistribución que alcance a la comunidad como tal. Eso obviamente genera problemas y desconfianza, y eso se ha manifestado, por ejemplo, en el Valle de la Luna, donde antes había una asociación encargada de la gestión y hoy día se ha tenido que ampliar también a otros sectores.

Creo que la visión del desierto atacameño como infinito, que no termina, que siempre se amplía, va permitiendo también que comunidades que no hayan tenido acceso o hayan tenido menos acceso a los ingresos por turismo busquen tomar otros sectores de la región para abrirlos a visitas. Por ejemplo, el manejo de la zona de Tara, donde hay unas formaciones rocosas alargadas muy llamativas, correspondería a la comunidad de Toconao, pero hoy día eso no tiene una administración formal, el acceso es libre. Todos los tour operadores saben que eso pertenece a Toconao, porque está en las tierras de ese ayllu y porque hay estudios desde los 90' que demuestran que esa zona rocosa se utilizaba, entre otras cosas para pastoreo; había un vínculo con ese espacio. Eso está reconocido, que la zona pertenece a ese ayllu, pero por el momento no hay control territorial, ni control de acceso. Posiblemente pronto, a medida que aumente la presión turística, sí lo va a haber. Si uno compara unos años atrás, hoy día el cambio es notable: hoy hay más lugares para visitar.

Hay también que tener en cuenta que es súper difícil el control del acceso a todo este territorio atacameño por parte de las instituciones del Estado. CONAF, que tiene las competencias de administración, tiene muy pocos funcionarios. Esto se esgrime como argumento a favor de la cesión del manejo de lugares con atracción turística, presentándolo como un acuerdo que beneficia tanto al Estado en su función de conservación de espacios naturales, como a las comunidades locales, que obtienen ingresos cobrando entradas y demás. También permite tener guías likanantai en estos lugares, y cierto tipo de infraestructura con sello likanantai o atacameño.

En cambio Rapa Nui es un espacio concebido como mucho más finito, al ser isla. $Y$ ahí CONAF, según su visión institucional, perfectamente podría llevar el control del Parque Natural de la isla. Pero la posición de los rapa nui es que con CONAF no hay suficiente control porque sus funcionarios no son capaces de hacer respetar los lugares tradicionales de los rapa nui, y porque no se les deja espacios propios para ellos y porque, en fin, el parque es parte de su territorio. El caso de los rapa nui 
es muy interesante, porque lo que contaban en el coloquio es que lograron conformar una comunidad indígena, Ma' u Henua, que es la que está a cargo del parque. ¿Qué pasa en otros lugares? ¿Qué pasa por ejemplo con las comunidades mapuche y atacameñas? Que son múltiples comunidades mapuche, o son varios ayllu, y entonces no hay posibilidad de tener un control unificado sobre los parques y zonas de atractivo turístico. Tampoco permite generar una estrategia tan clara.

En el caso de La Araucanía hay múltiples organizaciones mapuche, múltiples comunidades indígenas, en un mismo territorio podemos tener diez, veinte, treinta comunidades indígenas, treinta presidentes comunitarios, uno o dos lonkos (líder tradicional mapuche). Entonces, uno dice ¿por qué los mapuche no han tenido este reclamo, este acceso a las áreas protegidas del Estado? Porque ciertamente ha habido intentos. Pero, ¿a quién se les da derechos, quiénes van a administrar? Cuando se le da derechos a un grupo o comunidad particular, generas conflicto con otras; se interpreta como que el Estado beneficia a unos y otros quedan abajo, y se generan disputas muy fuertes entre las propias comunidades. Eso ha pasado históricamente por los efectos de una variedad de políticas públicas hacia los pueblos indígenas que, en el caso mapuche, desarticularon las formas tradicionales de organización.

Además, en La Araucanía no opera la concepción de infinito, al contrario; aquí las tierras indígenas son reducidas, y todo el resto está en manos de particulares, incluyendo muchas zonas con atractivos turísticos que explotan esos particulares. También hay muchas tierras que son agrícolas o forestales, y se produce así una presión sobre la tierra que es diferente a la de Rapa Nui o Atacama. Así, aunque el pueblo mapuche ha aparecido en Chile históricamente como el más reivindicativo y visible en su demanda territorial, es el que menos control territorial tiene ahora que llega el turismo como actividad económica.

[LFAF]: Una última pregunta ¿Qué balance haces tú, como coordinadora del evento, de este coloquio que reunió a gente de todo Chile, pero también de Argentina, de Brasil, y que puso en diálogo a agentes turísticos indígenas y no indígenas, a académicos, a funcionarios, a tour operadores y a mucha otra gente vinculada a este sector emergente que es el turismo?

[FdM]: Destacaría dos aspectos. Primero, la posibilidad de encontrarse generada para diferentes actores. Segundo, la generación de redes. Creo que fue un logro, sobre todo a nivel nacional. Es relevante también la participación de gente de Brasil y Argentina, que te permite tener una visión comparativa, pero creo que lo más provechoso del coloquio fue que los participantes, sobre todo los líderes y emprendedores indígenas, pudieran conocer lo que está pasando en otros territorios. Es tan evidente la prominencia del turismo que preocupa que la antropología no haya abordado con mayor fuerza estos temas, son procesos que realmente están transformando muchos territorios. Y los habitantes de estos territorios interesados en desarrollar el turismo se encuentran con dificultades a veces comunes, como por ejemplo la presencia de proyectos extractivistas.

Está también la disputa por las marcas, por los usos de los símbolos y otros elementos cultu- 
rales en el negocio turístico, y las disputas entre agentes internos y externos por su definición, propiedad y uso. También están las dificultades que tiene el mismo sistema estatal para generar emprendimientos turísticos, y todo esto se traduce en nuevos problemas en las relaciones históricas entre los pueblos indígenas y el Estado chileno. En el fondo el turismo pasa a ser un reflejo de esa relación.

Pero también hay muchos actores que ven el turismo como una oportunidad de reivindicación política o territorial indígena. Desde la gente que se tiraba en balsa por el río Bío Bío, que resignifica un conflicto tremendo en su territorio, de generación de represas, de muertes, de enfrentamientos; lo resignifican tirándose en la balsa con un discurso que también reivindica la historia. Y eso también está presente en las experiencias que se presentaron.

Respecto a las instituciones públicas, siento que todavía es muy sesgada la visión que tienen. Por ejemplo, me pareció que repitieron un par de veces esto del referente de los emprendedores (me refiero a la contraparte

\section{Referencias bibliográficas}

De la Maza, F. (2018a). Tourism in indigenous territories: the impact of public policies and tourism value of indigenous culture. Latin American and Caribbean Ethnic Studies, 13(1), 94-111.

De la Maza, F. (2018b). Gobierno local, política y turismo indígena institucional), y yo creo que no hay un referente, hay muchos referentes y ahí también se refleja la influencia que tienen algunos de los actores no indígenas en la definición de políticas públicas. Eso preocupa, por el rol que tienen las universidades también en ese tipo de discusión, y que a veces agentes externos que son los "expertos", entre comillas, pasan a tomar un rol central en la conformación de las redes indígenas, restándole también la propia agencia a los emprendedores. Ese tipo de discusión se dio en el coloquio, que sobre todo generó redes, conocimiento, intercambio. Creo que fue un hito importante, mucha gente decía que había pasado algo similar el 2015, pero que entonces no estaba instalado todavía el concepto de turismo indígena ni de turismo mapuche tanto como ahora. El 2015 fue como el hito para comenzar a discutir en políticas públicas lo que fue el turismo indígena, lo que generó diversos proyectos después a nivel nacional. Nosotros como academia pudimos generar un espacio más horizontal donde todos éramos actores y podíamos hablar en una misma mesa sin hacer tantas diferencias como se suelen hacer.

indígena: enfoque etnográfico en contextos interculturales. Revista Antropologías del Sur, 5(9), 181-195.

De la Maza, F. (2016). State conceptions of indigenous tourism in Chile. Annals of Tourism Research, 56: 80-95. 